\title{
Patient-controlled analgesia with fentanyl provides effective analgesia for second trimester labour: a randomized controlled study
}

\author{
[L'analgésie auto-contrôlée avec du fentanyl est efficace pendant le travail \\ obstétrical du second trimestre : une étude randomisée et contrôlée]
}

Carmencita Castro MD, ${ }^{*}$ Umamaheswary Tharmaratnam MB,${ }^{*}$ Nicole Brockhurst RN, $\dagger$ Luminita Tureanu MD, $\dagger$ Kenny Tam RN, $†$ Rory Windrim MD

Purpose: To examine dose and lockout intervals for effective fentanyl patient-controlled analgesia (PCA) in second trimester genetic termination of pregnancy, and compare three different fentanyl PCA regimes with morphine PCA.

Methods: In a double-blind randomized study, 60 ASA physical status I-II patients received one of three fentanyl PCAs or morphine PCA. Labour was induced with prostaglandins and PCA use continued until delivery. Within two hours following delivery, four visual analogue scales (VAS) were administered measuring anticipated pain, pain relief in labour and delivery, and overall satisfaction. The drug delivery/demand ratio for two hours preceding delivery was obtained from the PCA pump. The outcome variables were analyzed using the Chi square test and analysis of variance as appropriate.

Results: The delivery/demand ratio was $0.71 \pm 0.27$ (mean \pm standard deviation) for morphine; $0.67 \pm 0.21$ for fentanyl $50 \mu$ g, lockout six-minute; $0.63 \pm 0.21$ for fentanyl $25 \mu \mathrm{g}$, lockout threeminute; and $0.81 \pm 0.17$ for fentanyl $50 \mu$ g, lockout three-minute groups. We found no significant differences among the four groups with respect to using delivery/demand ratio as a measure of pain relief. Morphine had the highest rate of side effects compared to fentanyl. There was strong evidence of differences among groups with regard to patient satisfaction and expected pain, and moderate evidence of differences in the delivery and labour pain scores.

Conclusion: This study found PCA fentanyl $50 \mu \mathrm{g}$ with a lockout period of six minutes provided satisfactory analgesia for second trimester labour.
Objectif : Déterminer la dose et les périodes réfractaires d'une analgésie auto-contrôlée (AAC) efficace utilisée en cas d'interruption de grossesse génétique, et comparer trois régimes d'AAC avec fentanyl à la morphine en AAC.

Méthode : Pendant l'étude randomisée et à double insu, 60 patientes d'état physique ASA I-II ont reçu l'un des trois régimes de fentanyl en AAC ou de la morphine en AAC. Le travail a été induit avec des prostaglandines et l'AAC continue a été utilisée jusqu'à l'accouchement. Pendant les deux premières heures après l'accouchement, la douleur attendue, le soulagement de la douleur du travail et de l'accouchement et la satisfaction générale ont été évalués grâce à quatre échelles visuelles analogiques (EVA). Pendant les deux heures précédant l'accouchement, le ratio offre/demande de médicaments a été révélé par les données de la pompe à AAC. Les variables des résultats ont été analysées par le test du Khi carré et l'analyse de la variance selon les besoins.

Résultats : Le ratio offre/demande de morphine a été de 0,71 $\pm 0,27$ (moyenne \pm écart type); de 0,67 $\pm 0,21$ pour la dose de $50 \mu \mathrm{g}$ de fentanyl et une période réfractaire de six minutes; de 0,63 $\pm 0,21$ pour $25 \mu \mathrm{g}$ de fentanyl et trois minutes réfractaires et de 0,81 $\pm 0,17$ pour $50 \mu \mathrm{g}$ de fentanyl et trois minutes réfractaires. Ce n'est donc pas une mesure idéale de résultat. La morphine, comparée au fentanyl, avait le taux le plus élevé d'effets secondaires. Une forte évidence de différence intergroupe a été notée quant à la satisfaction des patientes et à la douleur prévue, et une évidence modérée de différences de scores de douleur pendant le travail et l'accouchement.

Conclusion : L'étude montre que $50 \mu \mathrm{g}$ de fentanyl et une période réfractaire de six minutes offrent une analgésie satisfaisante pendant le travail du second trimestre.

From the Departments of Anesthesia, ${ }^{*}$ Nursing, $†$ and Obstetrics, $\ddagger$ Mount Sinai Hospital, Toronto, Ontario, Canada. Address correspondence to: Dr. Carmencita Castro, Department of Anesthesia, Mount Sinai Hospital, Toronto, Ontario M5G 1X5, Canada. Phone: 416-586-5270; Fax: 416-586-8664; E-mail: cslcastro@yahoo.com

Financial acknowledgements: Grant support was provided by the Striving for Excellence Fund, Mount Sinai Hospital, Toronto, Ontario, Canada.

Accepted for publication February 15, 2003.

Revision accepted September $8,2003$. 
S

ECOND trimester (14-24 weeks) terminations of pregnancy are frequently performed for fetal anomalies incompatible with life. Traditionally, labour has been induced by intra-amniotic injection of prostaglandin F2 $\alpha$. Recently, other prostaglandins, such as misoprostol, have been administered via the vaginal route, with favourable effects. ${ }^{1}$

Although there is extensive literature regarding the mechanism of prostaglandin termination of pregnan$\mathrm{cy}$, there is a paucity of data on pain relief in this group of patients. Before the use of patient-controlled analgesia (PCA), parenteral narcotics via the $i m$ or $s c$ route were commonly used for pain management. More invasive methods of pain control, such as epidural or intrathecal analgesia, are usually reserved for patients who have inadequate pain control with the above regimen, or for those who require surgical intervention.

PCA fentanyl has been used in our institution for patients undergoing second trimester pregnancy termination. Individual practitioners have arbitrarily selected the dose and lockout for any particular patient. In order to identify which PCA regimen would be most effective, we decided to conduct a comparative study examining drug, dosage and timing.

Our study sought to compare the efficacy of three regimens of PCA fentanyl to PCA morphine using drug delivery/demand ratio as a measure of second trimester labour analgesia. With an optimal bolus dose and lockout interval, every PCA demand will result in successful administration and the demand to delivery ratio will be one. We hypothesized that fentanyl would be a better analgesic than morphine because of its faster onset and shorter duration of action. Secondary outcome measures of the study were the incidence of side effects and subjective reports of pain relief and satisfaction among different dose regimens of PCA fentanyl and PCA morphine.

\section{Methods}

The Mount Sinai Hospital Ethics Committee approved a prospective randomized study in ASA physical status I-II women scheduled to have a second trimester (14-24 weeks) termination of pregnancy as a result of lethal fetal abnormalities. The sample size for our study was based on work by Gambling et al., 2 where labour analgesia was measured with a demand/delivery ratio. These authors demonstrated that 15 patients per group yields an $80 \%$ power to detect a difference of 0.3 in the demand ratio between groups. As we studied four different groups, our sample size was therefore 60 . After controlling for overall Type 1 error, our study had an $80 \%$ power to detect a difference of 0.22 in one of the four groups using analysis of variance (ANOVA).

Either intra-amniotic injection of prostaglandin F2 $\alpha$ or vaginal insertion of misoprostol was used to terminate pregnancy. The exclusion criteria included contraindication to narcotics, i.e., allergy; history of narcotic drug abuse or chronic use; significant maternal disease (e.g., severe asthma, cardiac, liver or kidney disease); active bleeding or hypovolemia; moderate to severe pregnancy-induced hypertension; and inability to comprehend or comply with the PCA system of pain management.

Our research assistant explained the study to the patient and obtained an informed consent. A pharmacist randomized the participants to receive either the standard pump setting of morphine PCA or one of the three pump settings of fentanyl PCA. Patients were randomized in blocks using a random number table. The acute pain service nurse or the research assistant programmed the pump. The patient, the attending nurse, and the data collector were blinded to the type of narcotic and pump settings. To ensure blinding to the lockout interval, the PCA pump was programmed so that it beeped every time a demand button was pressed. Fifteen patients were assigned to each group. Programming of the PCA pump is shown in Table I. In order to ensure blinding, the medication was prepared by the hospital pharmacy.

The pump setting for the bolus dose was in millilitres. Therefore, in Group I, $1 \mathrm{~mL}$ of solution had $2 \mathrm{mg}$ of morphine; in Group II, $1 \mathrm{~mL}$ of solution had $50 \mu \mathrm{g}$ of fentanyl; in Group III, $1 \mathrm{~mL}$ of solution had $25 \mu \mathrm{g}$ of fentanyl; and in Group IV, $1 \mathrm{~mL}$ of solution had 50 $\mu \mathrm{g}$ of fentanyl. The $2 \mathrm{mg}$ dose of morphine was chosen because it is the most commonly used dose in our institution for second trimester terminations and it is within the PCA dose range recommended by previous studies for postoperative pain control. ${ }^{3,4}$ The clinician override was the same as the bolus dose. The nurse looking after the patient gave the clinician overrides but still was able to maintain blinding.

After the patient was admitted to the unit, labour was induced either by ultrasound-guided intra-amniotic injection of prostaglandin F2 $\alpha 40 \mathrm{mg}$ or vaginal insertion of $400 \mu \mathrm{g}$ of misoprostol every four hours, for a total of six doses, until delivery occurred. Intravenous access was established and the PCA pump was attached to the system. The PCA device (Graseby 3000, Watford, UK) consisted of a syringe pump activated by a handheld switch. The nurse gave detailed instructions for PCA use and monitored the heart rate, blood pressure, respiratory rate and sedation every second hour until the patient began use of the 
TABLE I Patient controlled analgesia pump programming

\begin{tabular}{lllll}
\hline & $\begin{array}{l}\text { Group I } \\
\text { Morphine }\end{array}$ & $\begin{array}{l}\text { Group II } \\
\text { Fentanyl }\end{array}$ & $\begin{array}{l}\text { Group III } \\
\text { Fentanyl }\end{array}$ & $\begin{array}{l}\text { Group IV } \\
\text { Fentanyl }\end{array}$ \\
\hline $\begin{array}{l}\text { Bolus dose } \\
\text { Lockout time } \\
\text { (min.) }\end{array}$ & $6 \mathrm{mg}$ & $50 \mathrm{mg}$ & $25 \mu \mathrm{g}$ & $50 \mu \mathrm{g}$ \\
Four-hour limit & $40 \mathrm{mg}$ & 6 & 3 & 3 \\
\hline
\end{tabular}

PCA pump. After the patient had begun to use the pump, assessment of respiratory rate and sedation was increased to every hour. The nurse also recorded any evidence of inadequate analgesia, side effects and treatment. For inadequate analgesia, clinician overrides, to a maximum of three doses every five minutes, were given by the attending nurse.

If significant pain persisted despite the overrides, the bolus was increased or the lockout period was shortened by the acute pain service staff. Epidural anesthesia was offered to those who had significant pain despite these measures. Treatment of side effects was standardized. The following medications were used: ondansetron $4 \mathrm{mg} i v$ was administered every six hours prn for nausea and vomiting, and nalbuphine 5-10 mg iv every six hours prn for pruritus. Nalbuphine was used because it works better than antihistamines for pruritus and it does not have potent sedating properties at low doses. Intermittent catheterizations, to a maximum of two times, were ordered for urinary retention. Sedation was rated by using the Fisher scale, developed in our department: S- normal sleep, 0- alert, 1- mild sedation, drowsy, opens eyes to name, 2 - moderate sedation, opens eyes to touch, 3- severe sedation, somnolent, difficult to rouse. For respiratory depression (a respiratory rate of less than $8 \cdot \mathrm{min}^{-1}$ ) or a sedation score of 3 on the Fisher scale, naloxone $0.2 \mathrm{mg} i v$ stat was ordered. For failed induction, iv oxytocin at $10 \mathrm{U} \cdot \mathrm{hr}^{-1}$ was administered until delivery.

\section{Data collection}

Demographic information and details of each patient's pregnancy history were obtained from the clinical record. These included maternal age, gravity, parity, prior abortions, any maternal health problems and indication for termination. All interventions for inadequate analgesia, side effects and treatments were obtained from the patient's clinical record.

A pilot study we conducted in a sample of eight women undergoing second trimester terminations of pregnancy indicated that the duration of labour was

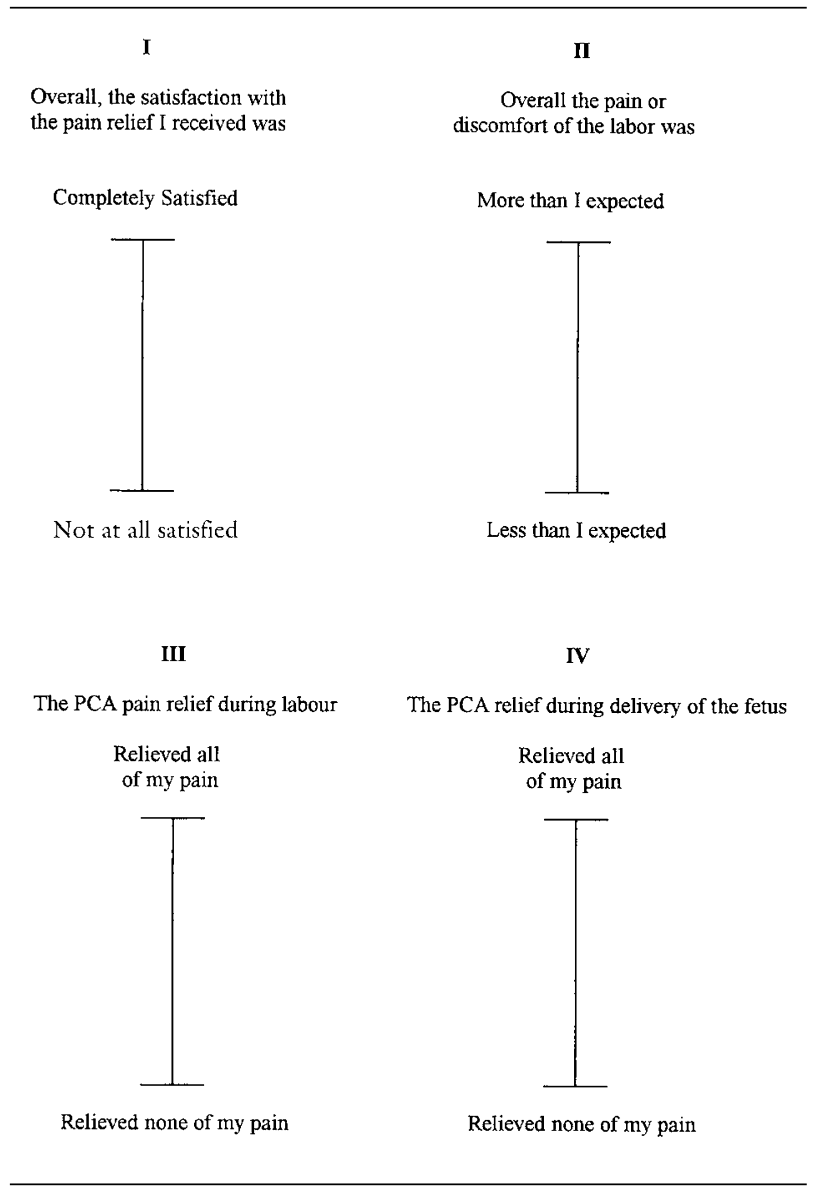

FIGURE 1 Visual analogue scales (VAS) used in the study.

variable in women after induction and that peak pain was experienced in the one or two hours before delivery and at delivery. Therefore, we began collecting data two hours preceding delivery, during which time the number of demands might be expected to exceed the number of doses delivered, and reflect the efficacy of the analgesic regimen.

In order to minimize the effect of delay on recall, all patients were seen by an independent observer within two hours of delivery. As soon as the patient's grief reaction allowed, within this two-hour period, she was provided with four visual analogue scales (VAS; $10 \mathrm{~cm}$ vertical) to assess the overall experience related to pain during labour and delivery (Figure 1). Each patient had the opportunity to provide additional comments on an exit questionnaire.

When the PCA pump was discontinued, the information was downloaded to a printer. Data from two hours before delivery were assessed for the total dose of the study medication received, number of demands 


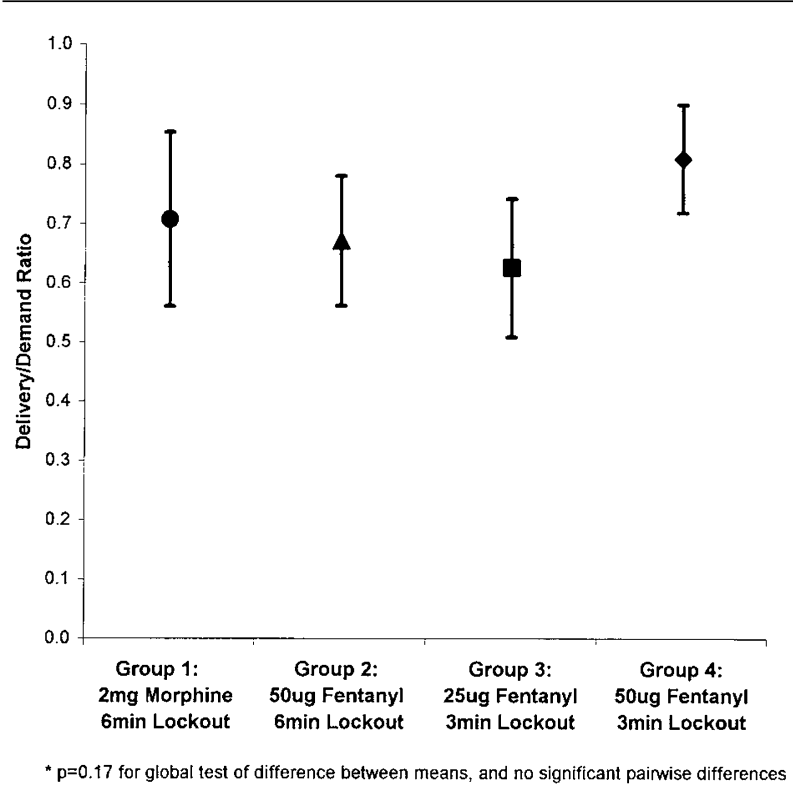

FIGURE 2 Mean delivery/demand ratios (95\% confidence interval) by treatment group*.

made and number of demands delivered. The progress of labour and complications were also collected from the patient chart after delivery.

\section{Statistical analysis}

Means and percentages of demographic and outcome variables were compared among different treatment regimes using the exact Chi square test for discrete variables, Poisson regression for count data (number of clinical overrides) and ANOVA for continuous variables. ANOVA residuals were examined visually to ensure that their distribution was approximately normal. A $P$ value of less than 0.01 was considered as strong evidence of differences between or among the groups, $0.01<P<0.05$ as moderate evidence, $0.05<$ $P<0.10$ as weak evidence, and $P>0.10$ signified no evidence of differences between or among groups. Pairwise comparisons were made between all groups (Groups II, III, and IV for total fentanyl dose) using the step down bootstrap approach, ${ }^{5}$ to adjust $P$-values for multiple comparisons. Adjusted $P$-values $<0.05$ were deemed to indicate a significant difference between two groups.

\section{Results}

Fifty-six women completed the study. Four patients were included in the intent-to-treat analysis. Three

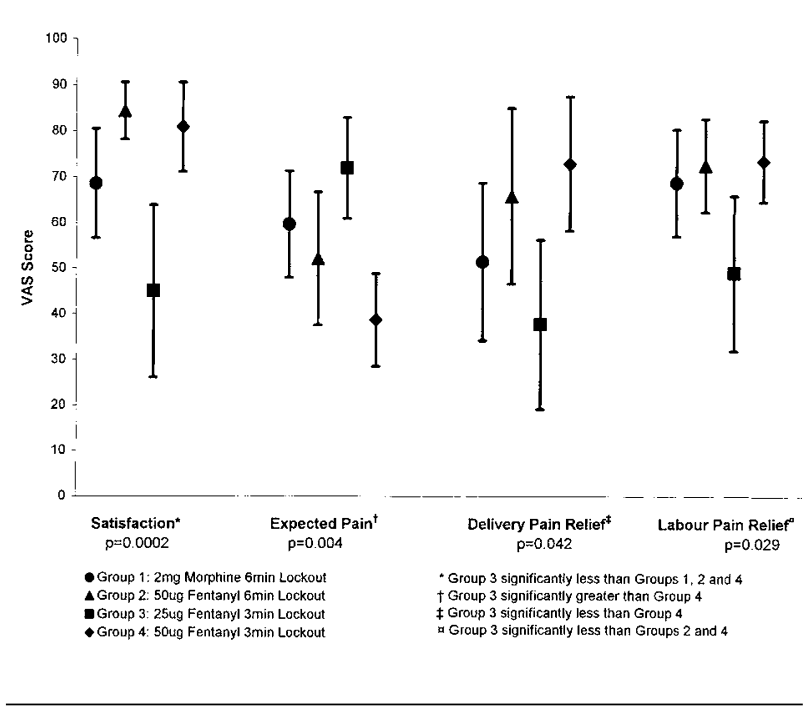

FIGURE 3 Visual analogue scale (VAS) score means (95\% confidence interval) by treatment group with global $p$-value and significant pairwise comparisons.

discontinued their assigned treatment: two patients in Group I due to severe side effects and one patient in Group III for inadequate pain relief. One patient in Group I did not use the PCA pump.

The demographic characteristics by group are shown in Table II. There were no statistically significant differences among groups for any of the variables examined.

There were no statistically significant differences in pain relief using delivery/demand ratio among the four groups compared (Figure 2). There was strong evidence of differences in patient satisfaction and expected pain relief, and moderate evidence of differences for delivery and labour pain relief (Figure 3). Whereas fentanyl $25 \mu \mathrm{g}$ group (Group III) had a significantly lower satisfaction score than any of the other groups, there was no evidence that the satisfaction scores for Groups I, II and IV were different from each other. The expected pain score for Group III (fentanyl $25 \mu \mathrm{g}$ every three minutes) was significantly higher than Group IV (fentanyl $50 \mu \mathrm{g}$ every three minutes). Expected pain was negatively correlated with each of the other VAS scores. These results were not changed when body weight and previous pregnancies were included as covariates in the analysis.

There was moderate evidence of a difference in the overall occurrence of side effects among groups. Vomiting and pruritus were the only two statistically 
TABLE II Comparison of demographic variables by treatment group

\begin{tabular}{|c|c|c|c|c|c|c|}
\hline & & $\begin{array}{l}\text { Group I } \\
2 \text { mg morphine } \\
\text { six-minute } \\
\text { lockout }\end{array}$ & $\begin{array}{l}\text { Group II } \\
50 \text { pg fentanyl } \\
\text { six-minute } \\
\text { lockout }\end{array}$ & $\begin{array}{l}\text { Group III } \\
25 \text { pg fentanyl } \\
\text { three-minute } \\
\text { lockout }\end{array}$ & $\begin{array}{l}\text { Group IV } \\
50 \text { ug fentanyl } \\
\text { three-minute } \\
\text { lockout }\end{array}$ & P-palue \\
\hline Maternal age & mean $(\mathrm{SD})$ & $32.7(7.4)$ & $32.0(5.8)$ & $30.7(3.6)$ & $31.1(6.7)$ & 0.81 \\
\hline $\begin{array}{l}\text { Gestational age (weeks) } \\
\text { Variable }\end{array}$ & mean $(\mathrm{SD})$ & $20.1(1.4)$ & $19.7(2.3)$ & $20.7(1.7)$ & $20.9(1.8)$ & 0.26 \\
\hline Body mass index $>25$ & $\%$ & $47 \%$ & $29 \%$ & $33 \%$ & $7 \%$ & 0.14 \\
\hline Nulliparous & $\%$ & $40 \%$ & $33 \%$ & $60 \%$ & $53 \%$ & 0.51 \\
\hline Previous pregnancy & $\%$ & $80 \%$ & $73 \%$ & $40 \%$ & $67 \%$ & 0.13 \\
\hline $\begin{array}{l}\text { Past use of patient } \\
\text { controlled analgesia }\end{array}$ & $\%$ & $7 \%$ & $0 \%$ & $13 \%$ & $7 \%$ & 0.90 \\
\hline
\end{tabular}

$\mathrm{SD}=$ standard deviation

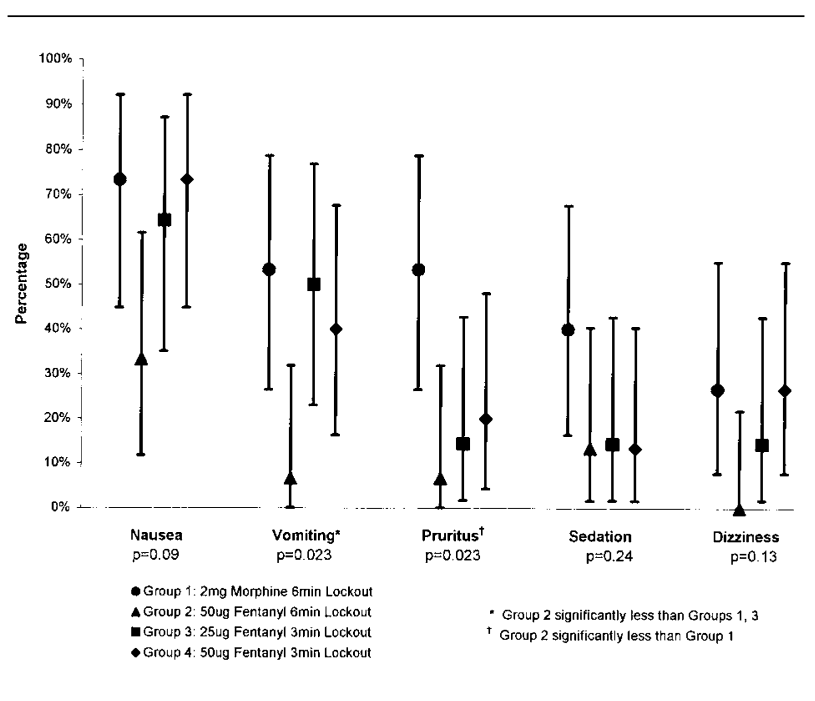

$\overline{\text { FIGURE } 4 \text { Percentage experiencing side effects (95\% confidence }}$ interval) by treatment group, with global $P$-value and significant pairwise comparisons.

significant side effects. The morphine group experienced the highest rate of side effects, while fentanyl groups experienced the lowest (Figure 4). Patients in Group II (fentanyl $50 \mu \mathrm{g}$ every six minutes) had significantly less vomiting than patients in Groups I and III. There was no incidence of respiratory depression and none of the patients required an epidural for inadequate pain relief. The large majority of the patients $(80 \%)$ from all groups was very satisfied with the PCA method of pain relief.

The number of clinician overrides was also analyzed using Poisson regression. With a $P$-value of 0.049 , there is evidence that the number of overrides differs among groups. However, this study does not have sufficient power to distinguish between any two treatment groups, so the ranking of groups should be interpreted with caution.

As this trial was analyzed on the basis of "intent-totreat", all four dropouts were included in the above analysis. For the primary outcome and the VAS scores, a supplemental analysis excluding dropouts was carried out to determine their impact on the analysis. For the delivery/demand ratio, the mean ratio for Group I (2 mg morphine, six-minute lockout) decreased to $0.654 \pm 0.259(n=11)$; however the $P$-value for the overall difference among groups changed from 0.17 to 0.13 , which does not change the conclusions about the lack of a difference between groups with respect to the delivery/demand ratio. Similarly, the $P$-values for the global test of significance dropped for each of the VAS scores $(P<0.0001, P=0.002,0.011$, and 0.012 , respectively for satisfaction, expected pain, delivery pain relief, and labour pain relief), strengthening the conclusions of the "intent-to-treat" analysis that each of these measures differed among groups.

There were no statistically significant differences in the total use of medication two hours preceding delivery among the fentanyl groups. Use amounted to 454 $\mu \mathrm{g}$ in Group II, compared to $291 \mu \mathrm{g}$ in Group III, and $503 \mu \mathrm{g}$ in Group IV.

\section{Discussion}

We report a double blind randomized controlled study of four different PCA regimens for second trimester genetic termination of pregnancy. With regard to the primary outcome measure of the study, we found no significant difference between the effectiveness of morphine and any of the three different fentanyl regimens, using delivery/demand ratios as a 
TABLE III Outcome measures by randomization group

\begin{tabular}{|c|c|c|c|c|c|c|}
\hline & & $\begin{array}{l}\text { Group I } \\
2 \text { mg morphine } \\
\text { six-minute } \\
\text { lockout }\end{array}$ & $\begin{array}{l}\text { Group II } \\
50 \text { ug fentanyl } \\
\text { six-minute } \\
\text { lockout }\end{array}$ & 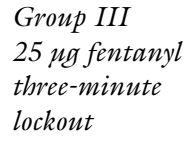 & $\begin{array}{l}\text { Group IV } \\
50 \text { mg fentanyl } \\
\text { three-minute } \\
\text { lockout }\end{array}$ & $\begin{array}{l}\text { Global } \\
P \text {-value* }\end{array}$ \\
\hline \multicolumn{7}{|l|}{ Primary outcome } \\
\hline \multicolumn{7}{|l|}{ Delivery/demand ratio } \\
\hline & mean & $0.707 \mathrm{~A} \dagger$ & $0.671 \mathrm{~A}$ & $0.626 \mathrm{~A}$ & $0.809 \mathrm{~A}$ & 0.17 \\
\hline & $\mathrm{SD}$ & 0.269 & 0.209 & 0.214 & 0.173 & \\
\hline & $n$ & 13 & 14 & 13 & 14 & \\
\hline \multirow{2}{*}{\multicolumn{7}{|c|}{$\begin{array}{l}\text { Visual analogue scale scores } \\
\text { Satisfaction }\end{array}$}} \\
\hline Satisfaction & & & & & & 0.0002 \\
\hline & SD & 23.6 & 11.8 & 33.4 & 19.2 & \\
\hline & $n$ & 15 & 14 & 12 & 15 & \\
\hline \multicolumn{7}{|l|}{ Expected pain } \\
\hline & mean & $59.7 \mathrm{AB}$ & $52.2 \mathrm{AB}$ & $72.0 \mathrm{~A}$ & $38.7 \mathrm{~B}$ & 0.004 \\
\hline & $\mathrm{SD}$ & 23.1 & 27.9 & 19.5 & 20.1 & \\
\hline & $n$ & 15 & 14 & 12 & 15 & \\
\hline \multicolumn{7}{|l|}{ Delivery pain relief } \\
\hline & mean & $51.5 \mathrm{AB}$ & $65.8 \mathrm{AB}$ & $37.7 \mathrm{~A}$ & $72.9 \mathrm{~B}$ & 0.042 \\
\hline & SD & 33.0 & 35.3 & 31.5 & 27.9 & \\
\hline & $n$ & 14 & 13 & 11 & 14 & \\
\hline \multicolumn{7}{|l|}{ Labour pain relief } \\
\hline & mean & $68.8 \mathrm{AB}$ & $72.6 \mathrm{~A}$ & $49.0 \mathrm{~B}$ & $73.5 \mathrm{~A}$ & 0.029 \\
\hline & $\mathrm{SD}$ & 23.1 & 19.4 & 30.0 & 17.6 & \\
\hline & $n$ & 15 & 14 & 12 & 15 & \\
\hline \multicolumn{7}{|l|}{ Side effects } \\
\hline \multicolumn{7}{|l|}{ One or more side effects } \\
\hline & $\%$ & $86.7 \% \mathrm{~A}$ & $46.7 \% \mathrm{~A}$ & $71.4 \% \mathrm{~A}$ & $86.7 \% \mathrm{~A}$ & 0.044 \\
\hline & $n$ & 15 & 15 & 14 & 15 & \\
\hline \multicolumn{7}{|l|}{ Nausea } \\
\hline & $\%$ & $73.3 \% \mathrm{~A}$ & $33.3 \% \mathrm{~A}$ & $64.3 \% \mathrm{~A}$ & $73.3 \% \mathrm{~A}$ & 0.09 \\
\hline & $n$ & 15 & 15 & 14 & 15 & \\
\hline \multicolumn{7}{|l|}{ Vomiting } \\
\hline & $\%$ & $53.3 \% \mathrm{~A}$ & $6.7 \% \mathrm{~B}$ & $50 \% \mathrm{~A}$ & $40 \% \mathrm{AB}$ & 0.023 \\
\hline & $n$ & 15 & 15 & 14 & 15 & \\
\hline \multicolumn{7}{|l|}{ Pruritus } \\
\hline & $\%$ & $53.3 \% \mathrm{~A}$ & $6.7 \% \mathrm{~B}$ & $14.3 \% \mathrm{AB}$ & $20.0 \% \mathrm{AB}$ & 0.023 \\
\hline & $n$ & 15 & 15 & 14 & 15 & \\
\hline \multicolumn{7}{|l|}{ Sedation } \\
\hline & $\%$ & $40.0 \% \mathrm{~A}$ & $13.3 \% \mathrm{~A}$ & $14.3 \% \mathrm{~A}$ & $13.3 \% \mathrm{~A}$ & 0.24 \\
\hline & $n$ & 15 & 15 & 14 & 15 & \\
\hline \multicolumn{7}{|l|}{ Dizziness } \\
\hline & $\%$ & $26.7 \% \mathrm{~A}$ & $0.0 \% \mathrm{~A}$ & $14.3 \% \mathrm{~A}$ & $26.7 \% \mathrm{~A}$ & 0.13 \\
\hline & $n$ & 15 & 15 & 14 & 15 & \\
\hline \multicolumn{7}{|l|}{ Additional outcomes } \\
\hline \multirow[t]{2}{*}{ Clinician overrides } & \# & $11 \mathrm{~A}$ & $7 \mathrm{~A}$ & $15 \mathrm{~A}$ & $2 \mathrm{~A}$ & 0.049 \\
\hline & $n$ & 15 & 15 & 14 & 15 & \\
\hline \multirow[t]{3}{*}{ Total dose in last two hours } & mean & $13.6 \mathrm{mg}$ & $454 \mu \mathrm{g} \mathrm{A}$ & $291 \mu \mathrm{g} \mathrm{A}$ & $503 \mu \mathrm{g} \mathrm{A}$ & $0.076 \ddagger$ \\
\hline & SD & 10.0 & 200 & 180 & 340 & \\
\hline & $n$ & 15 & 14 & 14 & 15 & \\
\hline
\end{tabular}

$\mathrm{SD}=$ standard deviation. ${ }^{*} P$-value for the global test of significance, against the null hypothesis that there are no differences among the four groups. $\nmid$ Letters $(A, B, \ldots)$ indicate pairwise comparisons of groups, i.e., two groups denoted by the same letter are not significantly different from each other using an alpha of 0.05 . ‡Comparing fentanyl groups II, III and IV only. 
measure of analgesic efficacy. As morphine is a lateonset analgesic compared to fentanyl, we had hypothesized a priori that patients receiving morphine would make more demands than could be delivered. However, the study results did not support this hypothesis. There was no evidence of an association between the delivery/demand ratio and any of the VAS scores, although there was significant $(P<0.05)$ correlation within the different VAS scores.

With regard to secondary outcomes, the morphine group had more side effects than the fentanyl groups. Fentanyl $50 \mu \mathrm{g}$ with a six-minute lockout had the lowest incidence of side effects and better patient satisfaction than the other groups. In this study, the dose of $25 \mu \mathrm{g}$ fentanyl appeared to be inadequate for pain relief, having significantly lower satisfaction scores than any other group, as well as the largest number of overrides. The satisfaction scores among the other three groups did not differ significantly.

Previous studies have concentrated on the postsurgical population and have demonstrated that PCA is a welltolerated and effective form of pain control when compared to traditional im narcotics. ${ }^{3,6,7}$ In the obstetrical population, PCA was first introduced in the $1990 \mathrm{~s},{ }^{8,9}$ however the popularity of epidural analgesia has meant that this method of pain control has been used only when epidural analgesia is contraindicated, or epidural service is not available. Rosenblatt et al. have presented the only research to date of PCA in this population. This group studied adjuncts to PCA for pain control in patients undergoing prostaglandin-induced pregnancy termination. ${ }^{10,11}$ These authors examined metoclopramide as an analgesic adjunct to PCA morphine and reported significantly reduced VAS pain scores in the metoclopramide groups. Although PCA is used in many centres in the management of pain during second trimester pregnancy termination, we were unable to find any published studies comparing different PCA drugs and dosages in order to determine the optimal regimen.

As termination of pregnancy for genetic indications in the second trimester is often both emotionally and physically arduous, any information that might optimize analgesia is valuable. It is important to determine the most appropriate PCA regimen because dosage studies have demonstrated that success of PCA (efficacy and absence of side effects) depends on the size of the demand dose. ${ }^{12}$ Too small a dose may result in failure to achieve adequate analgesia in the majority of patients, whereas too large a dose may result in adverse side effects. Similarly, the lockout interval influences success of the technique.

A variety of narcotics have been used for labour analgesia, including fentanyl, alfentanil and, most recently, remifentanil. ${ }^{14-23}$ Fentanyl has an onset of action within $30 \mathrm{sec}$, a peak effect in five to $15 \mathrm{~min}$ and a duration of action of 30 to $60 \mathrm{~min} .^{4,14}$ In addition, fentanyl has no adverse effects on uterine tone or blood flow and is rapidly removed from the plasma with more than $80 \%$ removal within five minutes and more than $98 \%$ within an hour. Fentanyl has no active metabolites to cause respiratory depression in the neonate. ${ }^{24,25}$ The published reports of PCA fentanyl for labour analgesia have used bolus doses varying from 20 to $60 \mu \mathrm{g}$, with and without continuous infusion, higher doses being associated with maternal respiratory depression. With our study population, the choice of narcotic was not limited by consideration of fetal effects. The shorter onset time and rapidity to achieve peak effect made fentanyl a suitable agent in our study. ${ }^{15,16}$

The main limitation of this study is the relatively small number of patients involved. Although randomization and blinding protocols were not violated, thereby avoiding most biases, there were four study arms in this trial of 60 patients and the study therefore has limited power to rule out a Type 2 error. Similarly, generalizability of our results to patients with different demographic profiles, such as parity, is limited by the size of the study. The clinical scenario for these patients, termination of a previously wanted pregnancy, presents many challenges to research in this area. In particular, single centre recruitment of a sufficiently large number of patients for adequate study power is unlikely, even in large centres. Therefore, additional studies are needed to expand upon our findings. Another limitation of the present study is the relative inadequacy of the tools used to measure our primary outcome measure. Pain scale score and side effects are somewhat limited evaluations of this little studied life experience, which for many women is both traumatizing and complex. A patient preferences global scoring system similar to those used for delivery at full term would evaluate broader factors, such as clouding of consciousness, and would be a more accurate tool for evaluating these analgesia regimens. Unfortunately, such a tool does not exist for genetic termination of pregnancy, although our group is developing and validating such a tool at present.

In conclusion, although limited by its size, this study is the first published research attempting to identify an optimal PCA regimen for second trimester termination of pregnancy. Employing the delivery/demand ratio as a measure of analgesia, PCA fentanyl was not more effective than PCA morphine for pain relief during termination. However, PCA morphine had the highest rate of side effects (pruritus and vomiting), while fen- 
tanyl $50 \mu \mathrm{g}$ (with a six-minute lockout) had the lowest rate of side effects. Based on these results, we recommend consideration of fentanyl $50 \mu \mathrm{g}$ with a six-minute lockout interval as the PCA regimen of choice for patients undergoing the ordeal of second trimester termination of pregnancy.

\section{Acknowledgements}

The authors gratefully acknowledge the cooperation of the seven south nursing staff and the labour-room respiratory therapists at Mount Sinai Hospital. We are grateful to Dr. Judith Littleford for her invaluable help in organizing and starting the study, to Robert Parkes of the Department of Biostatistics and Epidemiology of the Samuel Lunenfeld Research Institute for his statistical help, to Mary Mowbray for patient recruiting, and to Helen Robson for her editing assistance.

\section{References}

1 Davis VJ, Francoeur D, Grant L, Parish B, Steben M. Guidelines for medical termination of early pregnancy. Journal SOGC 1999; 82: 1169-74.

2 Gambling DR, Huber CJ, Berkowitz J, et al. Patientcontrolled epidural analgesia in labour: varying bolus dose and lockout interval. Can J Anaesth 1993; 40: 211-7.

3 Wasylak TJ, Abbott FV, English MJ, Jeans ME. Reduction of post-operative morbidity following patient-controlled morphine. Can J Anaesth 1990; 37: 726-31.

4 Austrup ML, Korean G. Analgesic agents for the postoperative period. Opioids. Surg Clin North Am 1999; 79: 253-73.

5 Westfall $P H$, Tobias RD, Rom D, Wolfinger RD, Hochberg $\Upsilon$. Multiple Comparisons and Multiple Tests. Using the SAS System. Cary, NC: SAS Institute Inc.; 1999.

6 Welchew EA. On-demand analgesia. A double-blind comparison of on-demand intravenous fentanyl with regular intramuscular morphine. Anaesthesia 1983; 38: 19-25.

7 Rosen M. Patient-controlled analgesia in practice. Semin Anesth 1986; 5: 108-11.

8 McIntosh DG, Rayburn WF. Patient-controlled analgesia in obstetrics and gynecology. Obstet Gynecol 1991; 78: 1129-35.

9 Crowhurst JA, Simmons SW. Patien-controlled analgesia in pregnancy. Int Anesthesiol Clin 1994; 32: 45-67.

10 Rosenblatt WH, Cioffi AM, Sinatra R, Saberski LR, Silverman DG. Metoclopramide: an analgesic adjunct to patient-controlled analgesia. Anesth Analg 1991; 73: $553-5$.

11 Rosenblatt WH, Cioffi AM, Sinatra R, Silverman DG. Metoclopramide-enhanced analgesia for prostaglandin- induced termination of pregnancy. Anesth Analg 1992; 75: 760-3.

12 Owen H, Plummer JL, Armstrong I, Mather LE, Cousins MJ. Variables of patient-controlled analgesia. 1. Bolus size. Anaesthesia 1989; 44: 7-10.

13 Howell PR, Gambling DR, Pavy T, McMortland G, Douglas MJ. Patient-controlled analgesia following caesarean section under general anaesthesia: a comparison of fentanyl with morphine. Can J Anaesth 1995; 42: 41-5.

14 Peng PW, Sandler AN. A review of the use of fentanyl analgesia in the management of acute pain in adults. Anesthesiology 1999; 90: 576-99.

15 Gavelin RJ, Jansen JA. IV fentanyl PCA during labour (Letter). Can J Anaesth 1992; 39: 1116-9.

16 Nikkola EM, Ekblad UU, Kero P, Alibanka JJ, Salonen $M A$. Intravenous fentanyl PCA during labour. Can J Anaesth 1997; 44: 1248-55.

17 Rosaeg OP, Kitts JB, Koren G, Byford LJ. Maternal and fetal effects of intravenous patient-controlled fentanyl analgesia during labour in a thrombocytopenic parturient. Can J Anaesth 1992; 39: 277-81.

18 Kleiman SJ, Wiesel S, Tessler MJ. Patient-controlled analgesia (PCA) using fentanyl in a parturient with a platelet function abnormality. Can J Anaesth 1991; 38: 489-91.

19 Thurlow JA, Waterhouse P. Patient-controlled analgesia in labour using remifentanil in two parturients with platelet abnormalities. Br J Anaesth 2000; 84: 411-3.

20 Jones R, Pegrum A, Stacey RG. Patient-controlled analgesia using remifentanil in the parturient with thrombocytopaenia. Anaesthesia 1999; 54: 461-5.

21 Lovell $M$, Elliott $D$. Use of remifentanil administered by PCA for analgesia during labour (Letter). Int J Obstet Anesth 2000; 85: 176-7.

22 Roelants F, De Franceschi E, Veyckemans F, Lavand'homme P. Patient-controlled intravenous analgesia using remifentanil in the parturient. Can J Anesth 2001; 48: 175-8.

23 Morley-Forster PK, Reid DW, Vandeberghe H. A comparison of patient-controlled analgesia fentanyl and alfentanil for labour analgesia. Can J Anesth 2000; 47: 113-9.

24 Koehntop DE, Rodman JH, Brundage DM, Hegland $M G$, Buckley JJ. Pharmacokinetics of fentanyl in neonates. Anesth Analg 1986; 65: 227-32.

25 Craft JB Jr, Coaldrake LA, Bolan JC, et al. Placental passage and uterine effects of fentanyl. Anesth Analg 1983; 62: 894-8. 